\title{
Relationship between lipid profiles and plasma total homocysteine, cysteine and the risk of coronary artery disease in coronary angiographic subjects
}

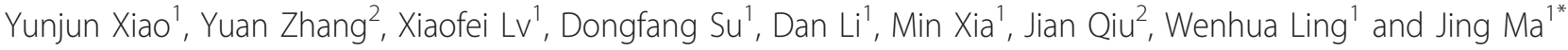

\begin{abstract}
Background: Homocysteine and cysteine are considered as risk factors of cardiovascular disease. Homocysteine influences the liver expression of ApoA-I and decreases its blood level and HDL in genetic mice model. We aimed therefore to evaluate whether homocysteine and cysteine are associated with lipid parameters, and the joint effects of them on the risk of coronary artery disease (CAD). Plasma total homocysteine (tHcy), cysteine (tCys) and lipid markers were measured in 2058 consecutive coronary artery angiographic patients.

Results: Plasma tHcy but not tCys correlated negatively with ApoA-I $(r=-0.153, P<0.001)$ and with HDL cholesterol $(r=-0.148, P<0.001)$, and correlated positively with the risk of CAD (OR: 1.61; 95\% confidence interval; 1.26 to 2.05). Combination of high tHcy and high tCys levels was associated with decreased ApoA-I and HDL cholesterol levels, and with increased risk of CAD (OR: 1.696, 95\% Cl (1.301-2.211)). Furthermore, low HDL cholesterol combined with low tHcy or high tHcy all had increased risk for CAD (OR: 1.254, 95\% Cl (1.114-1.565); OR: 1.332, 95\% Cl (1.093-1.624); respectively) whereas high HDL cholesterol counteracted the harmful effect of high tHcy on the risk of CAD. However, only the combination of high tHcy and high ApoA-I had an increased risk for CAD (OR: 1.438, 95\% Cl (1.170-1.768)).

Conclusions: The association of homocysteine and cysteine, ApoA-I or HDL cholesterol and their joint effects provide new insights on its role on CAD.
\end{abstract}

Keywords: Homocysteine, Cysteine, Lipid profiles, Coronary artery disease

\section{Introduction}

Hyperhomocysteinemia has been considered as an independent risk factor of coronary artery disease (CAD) $[1,2]$, but recent several large scale intervention studies found lowering the plasma total homocysteine (tHcy) with folic acid, vitamin $\mathrm{B}_{6}$ and $\mathrm{B}_{12}$ did not reduce the risk of cardiovascular disease [3]. Thus the cause-effect relationship of homocysteine and cardiovascular disease is controversial $[4,5]$. Furthermore, another sulf-containing amino acid cysteine, structurally like to homocysteine, was reported to be a risk factor of cardiovascular disease [6-8], but in prospective study, plasma total cysteine

\footnotetext{
* Correspondence: majing@mail.sysu.edu.cn

${ }^{1}$ Guangdong Provincial Key Laboratory of Food, Nutrition and Health; Department of Nutrition, School of Public Health, Sun Yat-sen University. 510080, Number 74 Zhongshan Road 2, Guangzhou, Guangdong, PR of China

Full list of author information is available at the end of the article
}

(tCys) was not an independent risk factor of cardiovascular disease [9]. The atherogenicity of homocysteine may involve several mechanisms including LDL-cholesterol oxidative modification, and HDL-cholesterol decrease [10]. Several studies reported homocysteine inhibited ApoA-I protein expression and decreased HDL cholesterol levels in vitro and animal model $[11,12]$. Cysteine is a vital structural and functional component of $A p o B$, the protein of LDL $[13,14]$. Though less reactive than homocysteine, cysteine exhibits autooxidation properties in the presence of metal ions which can support superoxidemediated modification of LDL, thus facilitating foam cell formation [15]. But the relationship between plasma tHcy, tCys levels and lipid profiles in CAD patients are still uncertain. Here, we investigated the relationship between plasma tHcy, tCys and the lipid parameters, and the joint effects of them on the risk of CAD.

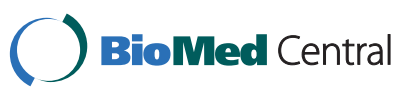

(c) 2011 Xiao et al; licensee BioMed Central Ltd. This is an Open Access article distributed under the terms of the Creative Commons Attribution License (http://creativecommons.org/licenses/by/2.0), which permits unrestricted use, distribution, and reproduction in any medium, provided the original work is properly cited. 


\section{Methods \\ Subjects}

The present cross-sectional study includes a total of 2,058 consecutive patients 40 to 85 years of age who had undergone a diagnostic coronary angiography at 3 hospitals (Guangzhou Military General Hospital, Sun Yat-Sen Memorial Hospital and Zhujiang Hospital) during December 2008 to September 2010 in Guangzhou, China. Those with medical illnesses such as acute infection, chronic hepatic dysfunction or nutritional derangements, malignancies, and other severe medical illnesses were excluded. All patients were free of drugs which would influence the plasma homocysteine levels, including folate or multivitamins. Of the 2,058 patients, The CAD patients $(n=1053)$ were defined as having significant stenosis in $\geq 1$ major coronary artery and those $(n=1005)$ who did not have significant stenosis of all arteries were defined as controls. Any instances of concomitant illness and any current medications were documented among our study subjects. We recorded 209 cases (10\%) with stroke, 108 individuals (5.2\%) with atrial fibrillation, 221 cases (10.6\%) of arrhythmia. The patients were accepted different medications that were $59.7 \%$ subjects who used statins; $60.3 \%$ patients used aspirin; $43 \%$ patients used beta-receptor blocker; $25 \%$ patients used angiotensin-converting enzyme inhibitor; $20 \%$ subjects used nitrates. All patients were gave informed consent to provide blood samples and the study was approved by hospitals ethics committee.

\section{Coronary angiography}

Coronary angiographies were performed using a standard Judkins technique through the femoral artery or brachial artery. The angiograms were interpreted by two or more independent cardiologists in a blind fashion. All evaluations were based on the American Heart Association method [16]. CAD was defined as diameter stenosis $\geq 50 \%$ in the left main, left anterior descending, left circumflex, and/or right coronary artery.

\section{Biochemical measurement}

After the patients had fasted overnight, blood samples were drawn into EDTA-containing tubes by venipuncture. Samples were immediately placed on ice and transported to the laboratory. Plasma and serum were prepared and stored at $-80^{\circ} \mathrm{C}$ until analysis. The plasma tHcy and tCys, which include the sum of protein-bound and free homocysteine and cysteine, were simultaneously measured by high-performance liquid chromatography with fluorescence detection [17]. The total serum cholesterol, triglyceride, and HDL cholesterol concentrations were determined enzymatically. LDL cholesterol was assayed using an indirect method. Apo A-I and ApoB were simultaneously measured by immunoassay.

\section{Statistical analysis}

Data are presented as medians and interquartile ranges for skewed variables. Unless otherwise indicated, values are expressed as mean $\pm \mathrm{SD}$ or as percentages for categorical variables. Comparisons between groups were performed using Kruskal-Wallis test followed where relevant by Mann-Whitney $U$ test with adjustment for multiple comparisons (continuous variables) or the chi-square test (categorical variables). Correlations between selected pairs of variables were evaluated with the spearman correlation and partial correlation with adjustment for age, gender and other factors. The tHcy and tCys were divided into quartiles for analysis. General linear model analysis was performed to evaluate the relationship between tHcy, tCys and the lipid profiles. In multiple logistic regressions, CAD was considered as a dependent variable, with appropriate adjustment for covariates.

The analyses were also performed for different combinations of low $(\leq 12 \mu \mathrm{mol} / \mathrm{L})$, high $(>12 \mu \mathrm{mol} / \mathrm{L})$ tHcy or low $(<219.5 \mu \mathrm{mol} / \mathrm{L})$, medium $(219.5-284.1 \mu \mathrm{mol} / \mathrm{L})$, high $(>284.1 \mu \mathrm{mol} / \mathrm{L}$ ) tCys. Subjects with combinations of low levels of tHcy and tCys served as the reference group. To evaluate joint effect of tHcy and HDL or ApoA-I on the risk of CAD, we also performed multiple logistic regressions and adjustment for other covariates with different combinations of low, high tHcy levels and high $(>1.05$ $\mathrm{mmol} / \mathrm{L})$, low $(\leq 1.05 \mathrm{mmol} / \mathrm{L}) \mathrm{HDL}$ cholesterol or high $(>1.17 \mathrm{mg} / \mathrm{L})$, low $(\leq 1.17 \mathrm{mg} / \mathrm{L})$ ApoA-I. Subjects with combinations of low levels of tHcy and high levels of HDL cholesterol or ApoA-I served as the reference group. Twoside $P$ values below 0.05 were considered to indicate statistical significance. All statistical analyses were performed using SPSS 13.0 software (SPSS Inc., Chicago, Illinois).

\section{Results}

\section{Clinical characteristics of subjects}

Table 1 shows the study population characteristics stratified by gender and presence or absence of CAD, $61 \%$ of the study population was male, and $51 \%$ had CAD. Mean age was $62.4 \pm 12.5$ years in the four subgroups. Plasma triglycerides, HDL cholesterol, ApoA-I, fasting plasma glucose were different in CAD cases relative to control, as were plasma concentrations of tHcy and creatinine. Plasma tCys levels were only increased in CAD cases compared to control in males.

Relationship between lipid profiles and plasma tHcy, tCys In spearman analysis (Table 2), plasma tHcy correlated negatively with plasma HDL cholesterol and Apo A-I levels $(\mathrm{r}=-0.148, P<0.001$ and $\mathrm{r}=-0.153, P<0.001$, respectively). By using covariance analyses (ANCOVA), the plasma HDL cholesterol and ApoA-I levels were found stepwise decreasing from lowest quartile to highest 
Table 1 Demographic and clinical characteristics of the study population $*$,

\begin{tabular}{|c|c|c|c|c|}
\hline \multirow[t]{2}{*}{ Characteristics } & \multicolumn{2}{|c|}{ Men } & \multicolumn{2}{|c|}{ Women } \\
\hline & $\begin{array}{c}\text { Control } \\
(n=562)\end{array}$ & $\begin{array}{c}\text { CAD } \\
(n=693)\end{array}$ & $\begin{array}{l}\text { Control } \\
(n=443)\end{array}$ & $\begin{array}{c}\text { CAD } \\
(n=360)\end{array}$ \\
\hline Age, yrs ${ }^{\ddagger} \S$ & $58.1 \pm 14.6$ & $63.7 \pm 11.4 \|$ & $61.4 \pm 12.5$ & $68.1 \pm 10.2^{\|}$ \\
\hline $\mathrm{BMI}, \mathrm{kg} / \mathrm{m}^{2}$ & $24.3 \pm 4.32$ & $24.7 \pm 4.01$ & $24.2 \pm 4.33$ & $24.6 \pm 3.41$ \\
\hline Smokers ${ }^{\ddagger}$ § & $186(33.1 \%)$ & $253(36.5 \%) \|$ & $7(1.6 \%)$ & $10(2.8 \%)$ \\
\hline Hypertension $\$$, & $315(56.0 \%)$ & $421(60.8 \%)$ & $269(60.7 \%)$ & $255(70.8 \%) \|$ \\
\hline Positive family history & $44(7.8 \%)$ & $31(4.5 \%)$ & $30(6.8 \%)$ & $30(8.3 \%)$ \\
\hline Total cholesterol, $\mathrm{mmol} / \mathrm{L}$ ₹, § & $4.63 \pm 1.03$ & $4.57 \pm 1.03$ & $4.91 \pm 1.06$ & $5.08 \pm 1.09 \|$ \\
\hline Triglycerides, $\mathrm{mmol} / \mathrm{L}$ & $1.82 \pm 1.24$ & $1.93 \pm 1.27 \|$ & $1.74 \pm 1.13$ & $1.95 \pm 1.19 \|$ \\
\hline LDL cholesterol, $\mathrm{mmol} / \mathrm{L}^{\S}$ & $2.95 \pm 0.90$ & $2.92 \pm 0.94$ & $3.04 \pm 0.94$ & $3.16 \pm 0.97$ \\
\hline $\mathrm{HDL}$ cholesterol, $\mathrm{mmol} / \mathrm{L} \neq, \S$ & $1.06 \pm 0.29$ & $1.03 \pm 0.34 \|$ & $1.22 \pm 0.30$ & $1.18 \pm 0.29 \|$ \\
\hline $\mathrm{ApoA}-\mathrm{I}, \mathrm{mg} / \mathrm{L}^{\ddagger}$ & $1.18 \pm 0.44$ & $1.11 \pm 0.32 \|$ & $1.31 \pm 0.46$ & $1.25 \pm 0.26 \|$ \\
\hline ApoB, mg/L & $0.77(0.64-0.88)$ & $0.76(0.61-0.89)$ & $0.78(0.64-0.90)$ & $0.80(0.65-0.97)$ \\
\hline $\mathrm{LpA}, \mathrm{mg} / \mathrm{L}$ & $0.32(0.25-0.44)$ & $0.34(0.24-0.47)$ & $0.33(0.26-0.41)$ & $0.34(0.26-0.45)$ \\
\hline LDL cholesterol/ApoB ratio & $3.87(3.46-4.23)$ & $3.81(3.42-4.21)$ & $3.88(3.45-4.29)$ & $3.82(3.51-4.21)$ \\
\hline Fasting plasma glucose, $\mathrm{mmol} / \mathrm{L}$ & $5.80 \pm 2.23$ & $6.19 \pm 2.43 \|$ & $5.98 \pm 2.45$ & $6.32 \pm 2.81 \|$ \\
\hline Creatinine, $\mu \mathrm{mol} / \mathrm{L}^{\ddagger}$ & $87.5(73.0-104)$ & $89.0(76.0-104) \|$ & $69.0(56.0-85.0)$ & $71.0(58.0-89.0) \|$ \\
\hline $\mathrm{tHcy}, \mu \mathrm{mol} / \mathrm{L}^{\ddagger}, \S$ & $13.8 \pm 5.93$ & $14.5 \pm 6.13 \|$ & $12.3 \pm 5.53$ & $12.9 \pm 6.08 \|$ \\
\hline tCys, $\mu \mathrm{mol} / \mathrm{L}$ & $248.4 \pm 46.3$ & $255.8 \pm 48.3 \|$ & $254.2 \pm 47.6$ & $251.3 \pm 45.5$ \\
\hline
\end{tabular}

* Values are mean $\pm \mathrm{SD}, \mathrm{n}(\%)$, or median (interquartile range)

† BMI and plasma variables in the four groups were compared by Kruskal-Wallis test followed where relevant by Mann-Whitney $U$ test with adjustment for multiple comparisons. $P<0.0125(0.05 / 4)$ was considered significant.

₹ Significantly different in men compared to women in the no CAD group.

$\S$ Significantly different in men compared to women in the CAD group.

|| Significantly different compared to no CAD group within the same gender.

quartile of tHcy after adjusted for age, gender and other confounders (all $P<0.001$ for trend) (Table 3).

In an attempt to investigate a combination variable of tHcy and tCys in relation to plasma HDL cholesterol and ApoA-I levels (Figure 1), we found the lowest HDL cholesterol and ApoA-I concentrations in subjects with high tHcy and tCys. There were significant linear trend decrease of HDL cholesterol and ApoA-I concentrations in all of the 6 tHcy-tCys combination groups with and without adjusted for age, gender and other confounders. However, no significance was showed the changes of HDL cholesterol and ApoA-I levels between the subgroups of low, medium, and high tCys levels in both low and high tHcy levels.

Table 2 Correlation coefficients of plasma tHcy, tCys and other characteristics

\begin{tabular}{|c|c|c|c|c|c|c|c|c|}
\hline & \multicolumn{4}{|c|}{$\mathrm{tHcy}(\mu \mathrm{mol} / \mathrm{L})$} & \multicolumn{4}{|c|}{ tCys ( $\mu \mathrm{mol} / \mathrm{L})$} \\
\hline & $r^{*}$ & $P$ & $r^{\dagger}$ & $P$ & $r^{*}$ & $P$ & $r^{\dagger}$ & $P$ \\
\hline $\mathrm{BMI}, \mathrm{kg} / \mathrm{m}^{2}$ & -0.021 & 0.684 & 0.038 & 0.467 & -0.014 & 0.790 & 0.022 & 0.677 \\
\hline Total cholesterol, mmol/L & -0.020 & 0.354 & 0.023 & 0.666 & -0.008 & 0.707 & 0.033 & 0.533 \\
\hline Triglycerides, mmol/L & -0.035 & 0.112 & 0.058 & 0.269 & -0.004 & 0.866 & 0.045 & 0.386 \\
\hline LDL cholesterol, mmol/L & -0.001 & 0.963 & 0.011 & 0.841 & -0.010 & 0.648 & 0.018 & 0.728 \\
\hline HDL cholesterol, mmol/L & -0.148 & $<0.001$ & -0.137 & 0.009 & -0.003 & 0.891 & 0.022 & 0.669 \\
\hline ApoA-I, mg/L & -0.153 & $<0.001$ & -0.135 & 0.010 & 0.029 & 0.189 & 0.018 & 0.735 \\
\hline ApoB, mg/L & 0.002 & 0.946 & 0.002 & 0.965 & -0.025 & 0.253 & 0.055 & 0.296 \\
\hline LpA, mg/L & 0.021 & 0.331 & -0.019 & 0.715 & 0.004 & 0.850 & -0.053 & 0.316 \\
\hline LDL cholesterol/ApoB ratio & -0.009 & 0.689 & 0.249 & $<0.001$ & 0.026 & 0.232 & 0.042 & 0.427 \\
\hline Fasting plasma glucose, $\mathrm{mmol} / \mathrm{L}$ & -0.009 & 0.677 & 0.040 & 0.441 & -0.016 & 0.476 & -0.067 & 0.199 \\
\hline Creatinine, $\mu \mathrm{mol} / \mathrm{L}$ & 0.207 & $<0.001$ & 0.228 & $<0.001$ & -0.011 & 0.629 & 0.026 & 0.616 \\
\hline
\end{tabular}

* Correlation between selected paired variables was analysis with spearman correlation.

† Correlation between selected paired variables was analysis with partial correlation adjusted for age, gender, smoke, hypertension, positive family history and coronary artery disease status.

Statistics for variables significantly associated with tHcy or tCys at $P<0.05$ are shown in bold. 
Table 3 Lipid profiles according to the quartiles of plasma tHcy and tCys levels *

\begin{tabular}{|c|c|c|c|c|c|}
\hline Variable & Q1 & Q2 & Q3 & Q4 & $P$ for trend \\
\hline tHcy $(\mu \mathrm{mol} / \mathrm{L})$ & $<9.1$ & $9.1-12.3$ & $12.4-16.5$ & $>16.5$ & \\
\hline Total cholesterol, $\mathrm{mmol} / \mathrm{L}$ & $4.66(4.57-4.76)$ & $4.81(4.72-4.89)$ & $4.73(4.64-4.82)$ & 4.79(4.69-4.88) & 0.126 \\
\hline Triglycerides, mmol/L & $1.89(1.77-2.02)$ & $1.78(1.66-1.90)$ & $1.93(1.81-2.05)$ & $1.85(1.73-1.97)$ & 0.383 \\
\hline LDL cholesterol, mmol/L & $2.93(2.85-3.01)$ & $3.03(2.95-3.11)$ & $3.00(2.92-3.08)$ & $3.04(2.96-3.12)$ & 0.266 \\
\hline $\mathrm{HDL}$ cholesterol, mmol/L & $1.15(1.14-1.17)$ & $1.14(1.13-1.16)$ & $1.08(1.07-1.10)$ & $1.05(1.03-1.06)$ & $<0.001$ \\
\hline ApoA-I, mg/L & $1.26(1.24-1.28)$ & $1.23(1.21-1.25)$ & $1.19(1.17-1.21)$ & $1.13(1.11-1.15)$ & $<0.001$ \\
\hline ApoB, mg/L & $0.76(0.74-0.79)$ & $0.80(0.77-0.83)$ & $0.82(0.79-0.85)$ & $0.79(0.76-0.82)$ & 0.094 \\
\hline $\mathrm{LpA}, \mathrm{mg} / \mathrm{L}$ & $0.36(0.32-0.40)$ & $0.46(0.42-0.49)$ & $0.38(0.35-0.42)$ & $0.40(0.37-0.44)$ & 0.001 \\
\hline LDL cholesterol/ApoB ratio & $3.87(3.64-4.10)$ & $3.85(3.63-4.08)$ & $4.07(3.85-4.30)$ & $3.88(3.65-4.13)$ & 0.481 \\
\hline tCys $(\mu \mathrm{mol} / \mathrm{L})$ & $<219.5$ & 219.5-250.2 & 250.3-284.1 & $>284.1$ & \\
\hline Total cholesterol, $\mathrm{mmol} / \mathrm{L}$ & $4.73(4.64-4.82)$ & $4.78(4.69-4.87)$ & $4.76(4.67-4.85)$ & $4.71(4.62-4.80)$ & 0.675 \\
\hline Triglycerides, mmol/L & $1.84(1.71-1.96)$ & $1.93(1.81-2.05)$ & $1.87(1.75-1.99)$ & $1.83(1.70-1.94)$ & 0.656 \\
\hline LDL cholesterol, mmol/L & $2.98(2.91-3.07)$ & $3.03(2.94-3.11)$ & $3.02(2.94-3.10)$ & $2.96(2.88-3.04)$ & 0.685 \\
\hline $\mathrm{HDL}$ cholesterol, mmol/L & $1.13(1.10-1.15)$ & $1.08(1.05-1.11)$ & $1.12(1.10-1.14)$ & $1.10(1.07-1.13)$ & 0.053 \\
\hline ApoA-I, mg/L & $1.13(1.09-1.17)$ & $1.14(1.10-1.18)$ & $1.19(1.15-1.24)$ & $1.12(1.08-1.17)$ & 0.141 \\
\hline ApoB, mg/L & $0.78(0.75-0.82)$ & $0.80(0.77-0.83)$ & $0.81(0.78-0.84)$ & $0.79(0.76-0.82)$ & 0.739 \\
\hline LpA, mg/L & $0.44(0.40-0.47)$ & $0.38(0.34-0.42)$ & $0.41(0.38-0.45)$ & $0.38(0.35-0.42)$ & 0.073 \\
\hline LDL cholesterol/ApoB ratio & $4.04(3.82-4.27)$ & $3.80(3.58-4.03)$ & $3.95(3.72-4.17)$ & $3.89(3.67-4.12)$ & 0.517 \\
\hline
\end{tabular}

* Data are presented as mean (95\% confidence interval). Analyses of covariance (ANCOVA) were performed using the general linear model approach after adjustment for age, gender, smoke, hypertension, fasting plasma glucose, and creatinine.

$P$ values are significant as shown in bold.

$\mathrm{Q} 1$ = quartile 1, Q2 = quartile 2, Q3 = quartile 3, Q4 = quartile 4

The association of plasma tHcy, tCys and the risk of CAD After additional adjustment for the age, gender and other potential confounders, plasma tCys showed no apparent association, high concentration of tHcy seemed to be associated with increased risk for CAD (OR: 1.34; 95\% CI (1.04-1.74)) (Table 4). We investigated a combination variable of tHcy and tCys in relation to the CAD risk (Figure 2A). Notably, the combinations of high tHcy and low (OR: 1.528, 95\% CI (1.161-2.011)), medium (OR: 1.358, 95\% CI (1.05-1.755)), or high tCys (OR: 1.696, 95\% CI (1.301-2.211)) all had significantly increased risk for CAD. However, after adjusted for age, gender and other confounders, only the combination of high tHcy and high tCys had a significantly increased risk for CAD (OR: 1.499, 95\% CI (1.137-1.976)).

\section{Combined effect of plasma tHcy and HDL, ApoA-I on the risk of CAD}

In the correlation analysis, we found plasma tHcy were associated negatively with plasma HDL cholesterol and ApoA-I levels, further, we investigated a combination variable of tHcy and HDL cholesterol or ApoA-I in relation to the CAD risk (Figure 2B). Interestingly, low HDL cholesterol combined with low tHcy or high tHcy all had increased risk for CAD (OR: 1.254, 95\% CI (1.114-1.565); OR: 1.332, 95\% CI (1.093-1.624); respectively) whereas combination of high HDL cholesterol and high tHcy had no significant association with the risk of CAD. In respect of combinations of tHcy and
ApoA-I, only the combination of high tHcy and high ApoA-I had an increased risk for CAD (OR: 1.438, 95\% CI (1.170-1.768)).

\section{Discussion}

In this cross-sectional study, our results showed significant negative relationship between plasma tHcy and HDL cholesterol or ApoA-I levels, positive dose-response relationship between plasma tHcy and the risk of CAD was observed. Furthermore, we found the joint effects of plasma tHcy and tCys decreased the plasma HDL cholesterol and ApoA-I levels, and increased the risk of CAD. In respect of joint effects of plasma tHcy and plasma HDL cholesterol or ApoA-I, low HDL cholesterol combined with both low and high tHcy increased the risk of CAD whereas only combination of high ApoA-I and high tHcy increased the risk of CAD.

Some reports showed a reduced expression of ApoA-I and decreased HDL cholesterol levels were observed in mice with genetically induced hyperhomocysteinemia. In the meth $\mathrm{r}^{+/}$deficient mice model, homocysteine reduced the expression of peroxisome proliferator-activated receptor (PPAR $\alpha$ ) and decreased the ApoA-I promoter activity and its protein levels [12]. In addition to its influence on ApoA-I, hyperhomocysteinemia inhibited reverse cholesterol transport by reducing circulating HDL via inhibiting apoA-I protein synthesis and enhancing HDL cholesterol clearance in the $\mathrm{cbs}^{-/-}$apoe $\mathrm{e}^{-/-}$mice [11]. Moreover, homocysteine associated with increased small size HDL3c 


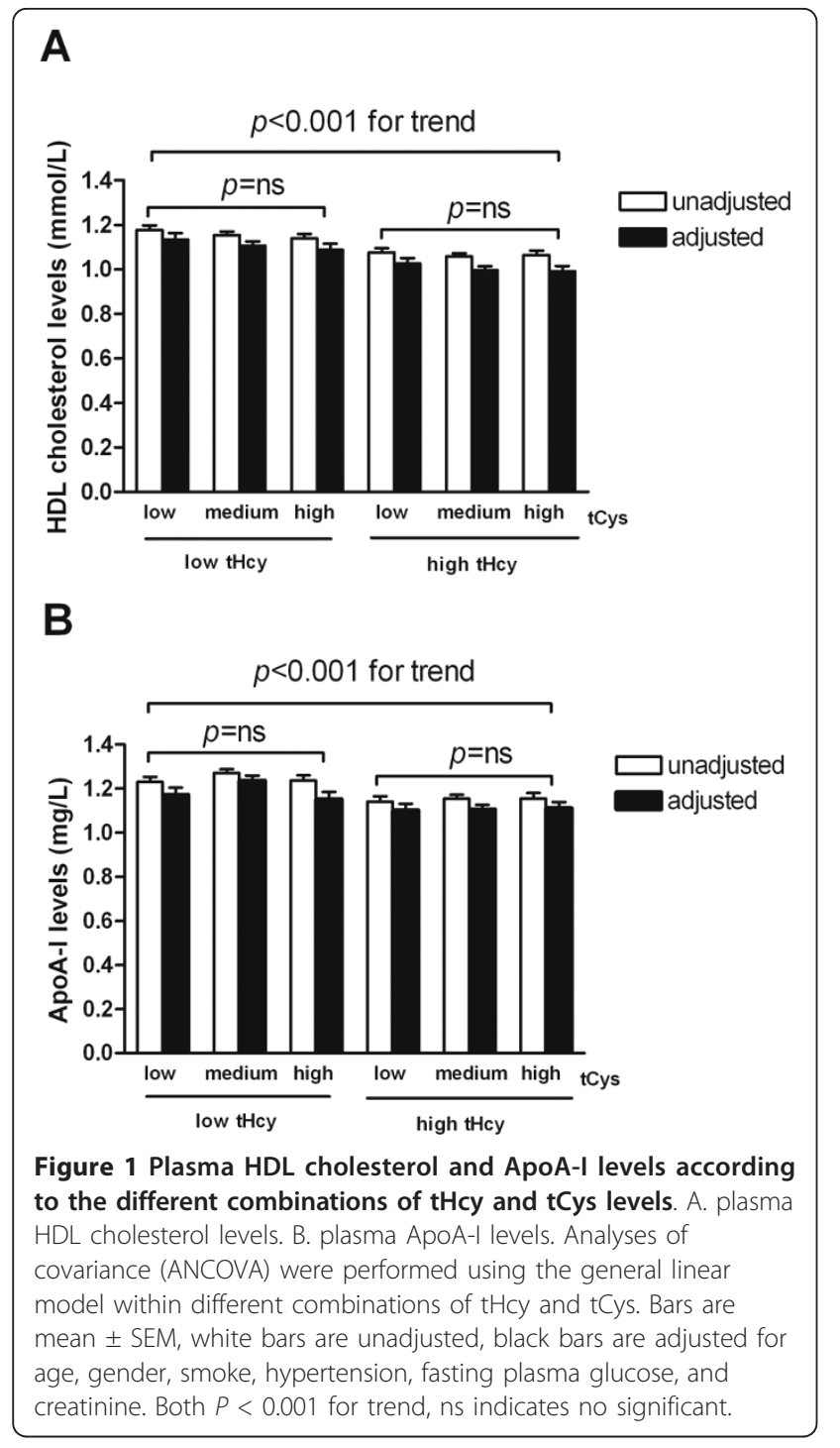

suggest mechanisms related with the impaired synthesis of ApoA-I and HDL and abnormal maturations of HDL particles [18].

Previous studies showed plasma tCys is positively related to cholesterol, diastolic blood pressure and BMI in Hordaland homocysteine study $[19,20]$, and positively correlated with fasting LDL cholesterol and ApoB in the COMAC cohort [8]. But in our present study, there was no significant association between plasma tCys and lipids levels. Because the blood samples in patients were drawn after the disease episode, however, we cannot rule out the possibility that $\mathrm{tCys}$ levels might be influenced by the disease itself. There is also the possibility that medication or change in lifestyle and dietary habits might have influenced the levels of tCys in our population [20]. In addition, several observations suggested that the role of cysteine in hepatic synthesis of ApoB may explain the epidemiology link of tCys and obesity [20-22].

Homocysteine and cysteine have been considered as risk factors of cardiovascular disease [8,23]. The studies concerning homocysteine lowering vitamin therapy did not mention the impact on cysteine levels [24,25]. We excluded the subjects who used vitamin supplement which might influence the plasma tHcy levels, but we can not rule out the effect of the dietary changes of the patients on the plasma tCys levels. It has been reported that large variations of cysteine levels in plasma which been observed in healthy subjects and this may be partly related to food intake [26]. Underlying nutrient disturbances may be an important determinant of plasma tCys levels. In addition, we did not select the health subjects as controls in our study population, this may be a selective bias of no association between plasma tCys and CAD.

Table 4 Unadjusted and adjusted risk for CAD prevalence with increasing quartiles of tHcy and tCys levels

\begin{tabular}{|c|c|c|c|c|c|}
\hline & Q1 & Q2 & Q3 & Q4 & $P$ for trend \\
\hline tHcy $(\mu \mathrm{mol} / \mathrm{L})$ & $<9.1$ & $9.1-12.3$ & $12.4-16.5$ & $>16.5$ & \\
\hline CAD & $228(44.5 \%)$ & 255(49.9\%) & $280(53.8 \%)$ & $290(56.3 \%)$ & \\
\hline Unadjusted OR (95\% Cl) & 1.0(referent) & $1.24(0.97-1.58)$ & $1.45(1.14-1.85)$ & $1.61(1.26-2.05)$ & $P<0.001$ \\
\hline Adjusted OR* (95\% Cl) & 1.0(referent) & $1.08(0.83-1.39)$ & $1.12(0.87-1.44)$ & $1.35(1.04-1.74)$ & $P<0.001$ \\
\hline Adjusted $\mathrm{OR}^{\dagger}(95 \% \mathrm{Cl})$ & 1.0(referent) & $1.04(0.80-1.36)$ & $1.14(0.88-1.47)$ & $1.34(1.03-1.74)$ & $P<0.001$ \\
\hline tCys $(\mu \mathrm{mol} / \mathrm{L})$ & $<219.5$ & $219.5-250.2$ & $250.3-284.1$ & $>284.1$ & \\
\hline CAD & $259(50.6 \%)$ & $261(50.5 \%)$ & $260(50.4 \%)$ & $273(53.2 \%)$ & \\
\hline Unadjusted OR (95\% Cl) & 1.0 (referent) & $0.99(0.78-1.27)$ & $0.98(0.77-1.26)$ & $1.11(0.87-1.42)$ & NS \\
\hline Adjusted OR* $(95 \% \mathrm{Cl})$ & 1.0(referent) & $1.04(0.81-1.34)$ & $1.05(0.82-1.35)$ & $1.16(0.90-1.49)$ & NS \\
\hline Adjusted $\mathrm{OR}^{\dagger}(95 \% \mathrm{Cl})$ & 1.0(referent) & $1.02(0.79-1.32)$ & $1.07(0.83-1.38)$ & $1.17(0.91-1.52)$ & NS \\
\hline
\end{tabular}

* Adjusted for age and gender.

† Adjusted for age, gender, smoke, hypertension, triglycerides, HDL, ApoA-I, fasting plasma glucose, creatinine.

$\mathrm{Cl}=$ confidence interval, $\mathrm{OR}=$ odds ratio, $\mathrm{Q} 1=$ quartile $1, \mathrm{Q} 2=$ quartile $2, \mathrm{Q} 3=$ quartile $3, \mathrm{Q} 4$ = quartile 4. 


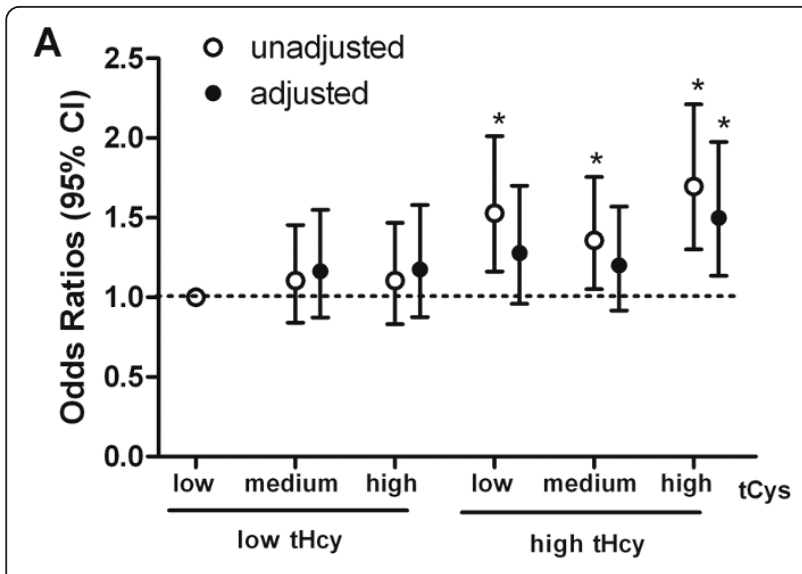

B

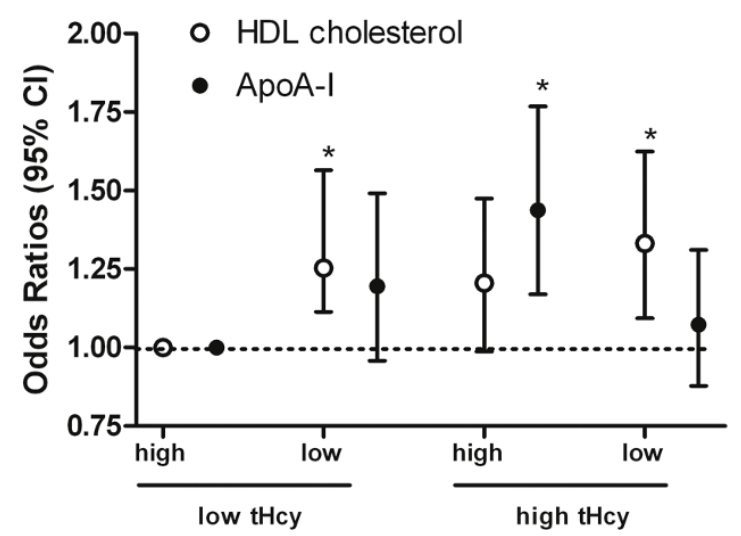

Figure 2 Combined effects of plasma tHcy and tCys, HDL cholesterol or ApoA-I levels on the risk of coronary artery disease prevalence. A. Within different combinations of tHcy and tCys, low levels of tHcy and tCys as reference group, odds ratios and 95\% confidence interval are from logistic regression analysis with and without controlling for age, gender, smoke, hypertension, triglycerides, $H D L$, ApoA-l, fasting plasma glucose, creatinine. B. Subjects with combinations of low levels of tHcy and high levels of HDL cholesterol or ApoA-I served as the reference group. ORs and 95\% Cl are from logistic regression analysis with controlling for age, gender, smoke, hypertension, triglycerides, fasting plasma glucose, creatinine. ${ }^{*} P<0.05$.

Further, the relation between tHcy and CAD was evaluated for different combinations of tHcy and tCys concentrations. The subjects with high tHcys and high tCys levels had the highest ORs for CAD with and without adjustment for potential confounders. However, there was no relation for CAD combined low tHcy levels with medium and high tCys levels, this indicates that the effects of high tCys on the risk of CAD are dependent on the associated levels of tHcy [8]. Moreover, the subjects with high tHcys and high tCys levels also had the lowest HDL cholesterol and ApoA-I levels. This may suggest the synergistic effects of tHcy and tCys decreased the plasma HDL cholesterol and ApoA-I levels and increased the risk of CAD $[7,27]$.
Next, we analyzed the joint effects of tHcy and HDL cholesterol or ApoA-I levels on the risk of CAD. Low HDL cholesterol levels combined with both low and high tHcy levels had significant ORs for CAD, it indicates that low HDL cholesterol levels was independent of plasma tHcy associated with the increased risk of CAD. On the contrary, the subjects with high HDL cholesterol levels and high tHcy levels had no significant OR for CAD, this may be explained that the protective effect of high HDL cholesterol levels could offset the harmful effect of high tHcy levels on the risk of CAD. On the other hand, the subjects with high ApoA-I levels and high tHcy levels did not have protective effect but increased the risk of CAD. Increased plasma tHcy levels correlated negatively with decreased ApoA-I and HDL cholesterol levels, and also positively with increased small size HDL3c [18]. So the subjects with high tHcy levels and high ApoA-I levels might have increased plasma small size HDL3c levels. This suggested the subjects with high tHcy levels which might impair the function of Apo-I and HDL and abnormal maturation of HDL particles although in presence of high ApoA-I levels would increase the risk of CAD.

\section{Conclusion}

our cross-sectional data showed that the plasma tHcy rather than $\mathrm{tCys}$ was associated with decreased plasma HDL cholesterol and ApoA-I levels and the increased risk of CAD. Further, we found plasma tCys was dependent on and increased the synergistic effect of plasma tHcy. However, plasma HDL cholesterol was independently and counteracted the effect of plasma tHcy. High plasma tHcy was associated with increased risk of CAD although in presence of high ApoA-I levels. Studies on the joint effects of plasma tHcy and other risk factors on the risk of CAD are therefore underway.

\section{Funding Sources}

This work was supported by grant from the Key Project (No.30730079) and grant (No.30872101) of National Natural Science Foundation of China.

\section{Abbreviations}

tHcy: total homocysteine; tCys: total cysteine; CAD: coronary artery disease; BMI: body mass index; ApoA-l: apolipoprotein A-l; ApoB: apolipoprotein B; HDL: high density lipoprotein; LDL: Iow density lipoprotein; LpA: lipoprotein A.

\section{Author details}

${ }^{1}$ Guangdong Provincial Key Laboratory of Food, Nutrition and Health; Department of Nutrition, School of Public Health, Sun Yat-sen University. 510080, Number 74 Zhongshan Road 2, Guangzhou, Guangdong, PR of China. ${ }^{2}$ Department of Cardiology, Guangzhou Military General Hospital. 510010, Number 111 Liuhua Road, Guangzhou, Guangdong, PR of China.

Authors' contributions

Conduct of the study: $Y Z, X L, D S$, 
Design and manuscript writing: $Y X, W L, J M$

Data collection and analysis: $\mathrm{DL}, \mathrm{MX}, \mathrm{JQ}$

All authors have read and approved the final manuscript.

\section{Competing interests}

The authors declare that they have no competing interests.

Received: 11 July 2011 Accepted: 12 August 2011

Published: 12 August 2011

\section{References}

1. Clarke R, Daly L, Robinson K, Naughten E, Cahalane S, Fowler B, Graham I: Hyperhomocysteinemia: an independent risk factor for vascular disease. The New England journal of medicine 1991, 324(17):1149-1155.

2. Ni M, Zhang $X H$, Jiang SL, Zhang Y: Homocysteinemia as an independent risk factor in the Chinese population at a high risk of coronary artery disease. The American journal of cardiology 2007, 100(3):455-458.

3. Lonn E, Yusuf S, Arnold MJ, Sheridan P, Pogue J, Micks M, McQueen MJ, Probstfield J, Fodor G, Held C, et al: Homocysteine lowering with folic acid and $B$ vitamins in vascular disease. The New England journal of medicine 2006, 354(15):1567-1577.

4. Brattstrom L, Wilcken DE: Homocysteine and cardiovascular disease: cause or effect? The American journal of clinical nutrition 2000, 72(2):315-323

5. Ueland PM, Refsum H, Beresford SA, Vollset SE: The controversy over homocysteine and cardiovascular risk. The American journal of clinical nutrition 2000, 72(2):324-332.

6. Araki A, Sako Y, Fukushima Y, Matsumoto M, Asada T, Kita T: Plasma sulfhydryl-containing amino acids in patients with cerebral infarction and in hypertensive subjects. Atherosclerosis 1989, 79(2-3):139-146.

7. Jacob N, Bruckert E, Giral P, Foglietti MJ, Turpin G: Cysteine is a cardiovascular risk factor in hyperlipidemic patients. Atherosclerosis 1999 146(1):53-59.

8. El-Khairy L, Ueland PM, Refsum H, Graham IM, Vollset SE: Plasma total cysteine as a risk factor for vascular disease: The European Concerted Action Project. Circulation 2001, 103(21):2544-2549.

9. El-Khairy L, Vollset SE, Refsum H, Ueland PM: Plasma total cysteine, mortality, and cardiovascular disease hospitalizations: the Hordaland Homocysteine Study. Clinical chemistry 2003, 49(6 Pt 1):895-900.

10. Austin RC, Lentz SR, Werstuck GH: Role of hyperhomocysteinemia in endothelial dysfunction and atherothrombotic disease. Cell death and differentiation 2004, 11(Suppl 1):S56-64.

11. Liao D, Tan H, Hui R, Li Z, Jiang X, Gaubatz J, Yang F, Durante W, Chan L, Schafer $\mathrm{Al}$, et al: Hyperhomocysteinemia decreases circulating highdensity lipoprotein by inhibiting apolipoprotein A-I Protein synthesis and enhancing HDL cholesterol clearance. Circulation research 2006 , 99(6):598-606

12. Mikael LG, Genest J Jr, Rozen R: Elevated homocysteine reduces apolipoprotein A-I expression in hyperhomocysteinemic mice and in males with coronary artery disease. Circulation research 2006, 98(4):564-571.

13. Huang XF, Shelness GS: Identification of cysteine pairs within the aminoterminal $5 \%$ of apolipoprotein B essential for hepatic lipoprotein assembly and secretion. The Journal of biological chemistry 1997, 272(50):31872-31876.

14. Smith CV, Jones DP, Guenthner TM, Lash LH, Lauterburg BH: Compartmentation of glutathione: implications for the study of toxicity and disease. Toxicology and applied pharmacology 1996, 140(1):1-12

15. Heinecke JW, Rosen H, Suzuki LA, Chait A: The role of sulfur-containing amino acids in superoxide production and modification of low density lipoprotein by arterial smooth muscle cells. The Journal of biological chemistry 1987, 262(21):10098-10103.

16. Austen WG, Edwards JE, Frye RL, Gensini GG, Gott VL, Griffith LS, McGoon DC, Murphy ML, Roe BB: A reporting system on patients evaluated for coronary artery disease. Report of the Ad Hoc Committee for Grading of Coronary Artery Disease, Council on Cardiovascular Surgery, American Heart Association. Circulation 1975, 51(4 Suppl):5-40.

17. Ubbink JB, Hayward Vermaak WJ, Bissbort S: Rapid high-performance liquid chromatographic assay for total homocysteine levels in human serum. Journal of chromatography 1991, 565(1-2):441-446.
18. Gueant-Rodriguez RM, Spada R, Moreno-Garcia M, Anello G, Bosco P, Lagrost L, Romano A, Elia M, Gueant JL: Homocysteine is a determinant of ApoA-I and both are associated with ankle brachial index, in an ambulatory elderly population. Atherosclerosis 214(2):480-485.

19. El-Khairy L, Ueland PM, Nygard O, Refsum H, Vollset SE: Lifestyle and cardiovascular disease risk factors as determinants of total cysteine in plasma: the Hordaland Homocysteine Study. The American journal of clinical nutrition 1999, 70(6):1016-1024

20. Elshorbagy AK, Nurk E, Gjesdal CG, Tell GS, Ueland PM, Nygard O, Tverdal A Vollset SE, Refsum H: Homocysteine, cysteine, and body composition in the Hordaland Homocysteine Study: does cysteine link amino acid and lipid metabolism? The American journal of clinical nutrition 2008, 88(3):738-746.

21. Elshorbagy AK, Valdivia-Garcia M, Graham IM, Palma Reis R, Sales Luis A, Smith $A D$, Refsum $H$ : The association of fasting plasma sulfur-containing compounds with BMI, serum lipids and apolipoproteins. Nutr Metab Cardiovasc Dis

22. Elshorbagy AK, Refsum H, Smith AD, Graham IM: The association of plasma cysteine and gamma-glutamyltransferase with BMI and obesity. Obesity (Silver Spring, Md 2009, 17(7):1435-1440.

23. Graham IM, Daly LE, Refsum HM, Robinson K, Brattstrom LE, Ueland PM, Palma-Reis RJ, Boers GH, Sheahan RG, Israelsson B, et al: Plasma homocysteine as a risk factor for vascular disease. The European Concerted Action Project. Jama 1997, 277(22):1775-1781.

24. Albert CM, Cook NR, Gaziano JM, Zaharris E, MacFadyen J, Danielson E, Buring JE, Manson JE: Effect of folic acid and B vitamins on risk of cardiovascular events and total mortality among women at high risk for cardiovascular disease: a randomized trial. Jama 2008, 299(17):2027-2036.

25. Ebbing M, Bleie O, Ueland PM, Nordrehaug JE, Nilsen DW, Vollset SE, Refsum H, Pedersen EK, Nygard O: Mortality and cardiovascular events in patients treated with homocysteine-lowering $B$ vitamins after coronary angiography: a randomized controlled trial. Jama 2008, 300(7):795-804

26. Guttormsen AB, Schneede J, Fiskerstrand T, Ueland PM, Refsum HM: Plasma concentrations of homocysteine and other aminothiol compounds are related to food intake in healthy human subjects. The Journal of nutrition 1994, 124(10):1934-1941.

27. Kinscherf R, Cafaltzis K, Roder F, Hildebrandt W, Edler L, Deigner HP Breitkreutz R, Feussner G, Kreuzer J, Werle E, et al: Cholesterol levels linked to abnormal plasma thiol concentrations and thiol/disulfide redox status in hyperlipidemic subjects. Free radical biology \& medicine 2003, 35(10):1286-1292

doi:10.1186/1476-511X-10-137

Cite this article as: Xiao et al.: Relationship between lipid profiles and plasma total homocysteine, cysteine and the risk of coronary artery disease in coronary angiographic subjects. Lipids in Health and Disease 2011 10:137.

\section{Submit your next manuscript to BioMed Central and take full advantage of:}

- Convenient online submission

- Thorough peer review

- No space constraints or color figure charges

- Immediate publication on acceptance

- Inclusion in PubMed, CAS, Scopus and Google Scholar

- Research which is freely available for redistribution

Submit your manuscript a www.biomedcentral.com/submit
C Biomed Central 